Original Research

\title{
The relationship between sleep duration and health status in Qatar's population
}

\author{
Maryam A. Al-Thani *, Salma M. Khaled, PhD, Associate Professor \\ Social and Economic Survey Research Institute, Qatar University, Doha, Qatar
}

A B S T R A C T

Knowledge of sleep duration correlates is limited to developed countries with a lack of studies in the Eastern Mediterranean Region (EMR). Qatar is a rapidly developing country in the EMR with three distinct population groups: Qatari nationals (QNs) or natives; higher income white-collar expatriates (WCEs), and bluecollar workers (BCEs) who are mostly male laborers from South Asia. The aim of this study was to explore the association between sleep duration, chronic health conditions, important lifestyle variables, and sociodemographic characteristics in a representative sample of Qatar's general population. A total of 2523 surveys were administered over the phone and a final sample of 2500 was retained. The overall prevalence of sleeping $<7 \mathrm{hrs}$ was observed at $54 \%$, while $42 \%$ of respondents reported sleeping 7-8hrs and 4\% reported sleeping $>8 \mathrm{hrs}$. Qatar's population exhibited low prevalence of normal sleep duration and high prevalence of short sleep duration. Participants who reported the poorest health status had increased odds of sleeping $<7 \mathrm{hrs}(\mathrm{OR} 1.38, \mathrm{P}=0.04)$ compared with those who reported good health after adjustment for covariates. Additionally, participants with two or more diagnosed illnesses had higher odds of sleeping $<7 \mathrm{hrs}(\mathrm{OR} 1.58, \mathrm{P}=0.02)$ compared to healthy participants. An increase in odds of sleeping $<7$ hrs was also observed in participants with obesity (OR $1.58, \mathrm{P}=0.02)$. Qatar's population exhibited high prevalence of short sleep duration, which was significantly associated with poor rated health, obesity, and chronic illness independent of age, gender, or social class.

\section{Introduction}

Sleep is a vital biological process for human health. Sleep is also a personal behavior subjected to social and environmental influences. Increasingly, sleep duration is considered a predictor of an individual's health status. Previous studies conducted in developed countries report a U-shaped relationship between sleep duration and all-cause mortality with short and long sleepers are considered at greater risk [1,2]. Additionally, a U-shaped association between self-reported health status and sleep duration was previously reported in which Asian countries with the shortest sleep duration also reported the poorest health rating. However, this U-shaped relationship is not consistent across all studies [3]. Additionally, there is no consistent evidence that overall sleep duration is declining in recent cohorts with Bulgaria, Poland, Canada, France, Britain, Korea and the Netherlands showing an increase, while Japan, Russia, Finland, Germany, Belgium and Austria report a decrease in total amount of sleep $[4,6,7]$. In light of the potential impact of sleep duration on health, public health efforts to improve sleep behavior are increasing worldwide. However, knowledge of correlates of sleep duration is limited to developed countries with dearth of studies conducted in countries of the Eastern Mediterranean Region (EMR).

Of particular interest is the association between short sleep and ill health as sufficient sleep is required for wellbeing and optimal function [8]. Obtaining sufficient sleep is becoming harder given our 24-h driven modern society. In addition, our increasing reliance on technology may also contribute to lack of sleep. For example, a recent study showed that prolonged exposure to artificial lighting via screen-based digital technology interrupted daily circadian sleep-wake cycle potentially contributing to shorter sleep duration [9]. Accumulating evidence over the past few decades also supports the association between insufficient sleep and many health conditions including cardiovascular disease, hypertension, stroke, type 2 diabetes, obesity, poor cognitive function, and poor mental health $[10,11]$. The link between short sleep duration and its adverse health effects are thought to be bidirectional with short sleep both a risk factor for and a symptom of poor health [35]. Unlike short sleep, there is currently insufficient information supporting plausible underlying biological mechanisms linking long sleep and disease [12].

Common mental disorders like depression, certain sociodemographic characteristics (low income, employment status, ethnicity), obesity, and poor lifestyle choices (smoking, physical inactivity) have been also associated with short and long sleep duration [14,15]. These variables are also known to be associated with higher morbidity and mortality [16]. As such, these variables may be important confounders or causal mediators of the association between sleep duration and ill health.

\footnotetext{
* Corresponding author.

E-mail addresses: Maryamalthani@qu.edu.qa (M.A. Al-Thani), skhaled@qu.edu.qa (S.M. Khaled).
} 
Qatar is a developing country in the EMR undergoing rapid economic growth, modernization, and sociocultural changes. There is a dearth of studies in Qatar and this region on potential predictors of short and long sleep duration and their associations with chronic disease in the general population. Most published studies report insufficient sleep in children and young adults of these populations [17-19]. A hospital-based study showed that 1 in every 3 Saudi adults reported short sleep duration [20]. Given little research exist on this topic in Qatar and other EMR countries; the aim of this study was to explore the association between sleep duration and chronic health conditions, important lifestyle variables, sociodemographic characteristics, depressive symptoms, and sleep duration in a representative sample of Qatar's general population.

\section{Material and methods}

\subsection{Survey administration}

The current study was approved by the Qatar University's institutional review board (IRB) and participants provided informed consent to participate in a survey conducted by Qatar University's Social and Economic Survey Research Institute on April of 2018 using computerassisted telephone interviewing. The interviewers received training and were monitored to ensure questions were asked appropriately and answers were recorded accurately. The survey was administered in nine most used languages among Qatar's population including Arabic, English, Urdu, Hindi, Malayalam, Nepalese, Bengali and Tamil.

\subsection{Study sample and characteristics}

Qatar has a diverse population with three distinct social classes or population groups sharing a similar social structure with most other countries in the Arabian Gulf. The first group is Qatari nationals (QNs) or natives; most are of tribal origins with shared ancestry and traditions. The second group is higher income white-collar expatriates (WCEs) who are highly skilled, educated, and come from all over the world. The third group is blue-collar workers (BCEs) who are mostly young male laborers from South Asia and South East Asia with little or no formal education. The target population of 18 years and over was sampled from three diverse social groups (QNs, WCEs, and BCEs) within Qatar's resident population.

Given the majority of adults in Qatar own at least one cellphone, our sample was selected from a frame of cellphone numbers using listassisted sampling technique [21]. A total of 10579 phone survey interviews were attempted of which 5872 constituted our target population, there were at least seven attempts to complete the survey for every phone number, after "hard refusal" or unable to reach numbers, a total of 2523 surveys were completed giving a response rate of $43 \%$. After removing cases for which sleep duration was unknown $(n=18)$ or refused $(n=1)$ and excluding data entry error of $0 h(n=4)$, a final sample of 2500 was retained. The final study sample consisted of 833 QNs, 935 WCEs, and 732 BCEs. The sample was weighted to account for sampling selection probability, non-response, and calibration to align estimates with known population characteristics available from Census bureau [22]. The weighted proportions of QNs, WCEs, and BCEs were $7.9 \%, 27.0 \%$, and $65.1 \%$, respectively.

\section{Measures}

\subsection{Sleep duration}

The average sleep duration was based on the following survey question: "On an average night, how many hours do you sleep?" To maintain power and precision, responses were collapsed into three categories: less than $7 \mathrm{hrs}, 7-8 \mathrm{hrs}$ and more than $8 \mathrm{hrs}$ based on previous literature of the U-shaped association and health related outcomes [23,24].

\subsection{Diagnosed chronic illness}

Chronic disease status was defined as having any of the following conditions in response to the following survey question and response options: "Have you been diagnosed or told by your doctor that you have any of the following conditions?" The list of health conditions included: "Hypertension or high blood pressure?", "Cardiovascular or heart disease?", "Diabetes?”, “Asthma?", "Gastrointestinal disorder?", "Depression?", "Other mental or Psychological Problems such as anxiety, or sleep problems?", "Cancer", "Disability (physical, mental, visual, hearing, etc.)", “Thyroid disorder?”, "Any other condition not mentioned?".

\subsection{Depression}

Depressive symptoms were assessed using the ultra-brief patient health questionnaire (PHQ-2) [25]. The performance of the PHQ-2 was reported to be acceptable compared to longer depression screening instruments. A score that ranges from 0 to 6 was computed, and a cutoff point $\geq 3$ was used as proxy-measure of clinically significant depression [26].

\subsection{Body Mass Index \& life style variables}

Body Mass Index (BMI) was calculated from self-reported weight and height measurements. Accordingly, participants were classified as underweight if $\mathrm{BMI} \leq 18.4$, normal weight if $\mathrm{BMI} \geq 18.5$ and $\mathrm{BMI} \geq 24.9$, and overweight or obese if BMI $\geq 25$. Sedentary behavior was measured using the question: "Physical activity or exercise includes activities such as walking briskly, jogging, team sports, or any other activity in which you breathe harder or feel warmer, do you currently engage in physical activity on a regular basis?" Smoking status was also assessed using the following question: "At the present time, do you smoke cigarettes daily, occasionally or not at all?" Responses were grouped into current versus non-current smoker (never and former smoker status). Perceived health status was measured on a scale from 0 to 100 using the question: "I would now like to ask you to imagine a scale that looks like a thermometer. The best health state you can imagine is marked 100 (one hundred) at the top of the scale and the worst state you can imagine is marked 0 (zero) at the bottom. I would now like you to tell me the point on this thermometer where you would rate your own health state today". Responses were categorized into three quantiles of "poor", "good" and "very good".

\subsection{Statistical analysis}

Descriptive analysis explored characteristics of the sample. Weighted proportions with corresponding 95\% confidence intervals (CI) were used to account for the complex survey design and nonresponse. To correct for survey design effects on the variances of reported proportions, the Ftransformed version of the Pearson Chi-square statistic was used.

Multinomial logistic regression models with sampling weights that account for complex survey design were used to examine the association between socioeconomics, lifestyle variables, and health characteristics that could potentially determine sleep duration (dependent variable). All models were adjusted for age, gender and social group/class. Statistical significance was determined using an alpha value of 0.05 . All analyses were conducted in STATA 14.

\section{Results}

Characteristics of the sample in relation to sleep duration are shown in Table 1. Overall, high prevalence of short sleep duration was observed at $54 \%$, while $42 \%$ of respondents reported normal, and $4 \%$ reported long sleep durations, respectively. The highest proportion of short sleepers was in BCE (58\%) and of long sleepers was in QNs (8\%).

Multinomial logistic regression models are presented in Table 2 that show associations between socioeconomics and sleep duration. WCEs 
Table 1

Sleep duration by sample characteristics.

\begin{tabular}{|c|c|c|c|c|c|c|c|}
\hline \multirow[t]{2}{*}{ Sleep duration } & \multicolumn{2}{|c|}{ Short ( $<7$ hrs) } & \multicolumn{2}{|c|}{ Normal (7-8 hrs) } & \multicolumn{2}{|c|}{ Long ( >8 hrs) } & \multirow[b]{2}{*}{ P-value } \\
\hline & $\%$ & CI & $\%$ & CI & $\%$ & CI & \\
\hline Overall $(n=2500)$ & 54.35 & $51.25-57.42$ & 42.13 & $39.11-45.21$ & 3.52 & $2.64-4.68$ & NA \\
\hline \multicolumn{8}{|l|}{ Respondent Group } \\
\hline Qataris $(\mathrm{n}=833)$ & 52.81 & $49.30-56.30$ & 38.86 & $35.49-42.33$ & 8.33 & $6.53-10.57$ & \multirow[t]{3}{*}{$<0.001 *$} \\
\hline White collar Expats $(\mathrm{n}=935)$ & 45.56 & $41.55-49.63$ & 50.41 & $46.33-54.49$ & 4.02 & $2.65-6.07$ & \\
\hline Blue collar Expats $(\mathrm{n}=732)$ & 58.18 & $53.75-62.47$ & 39.09 & $34.86-43.49$ & 2.73 & $1.66-4.46$ & \\
\hline \multicolumn{8}{|l|}{ Gender } \\
\hline Male $(\mathrm{n}=1807)$ & 55.99 & $52.42-59.50$ & 40.99 & $37.53-44.54$ & 3.02 & $2.07-4.38$ & \multirow[t]{2}{*}{$0.004^{*}$} \\
\hline Female $(n=693)$ & 46.89 & $41.44-52.42$ & 47.31 & $41.81-52.87$ & 5.80 & $4.02-8.31$ & \\
\hline \multicolumn{8}{|l|}{ Marital status } \\
\hline Married $(\mathrm{n}=1747)$ & 56.17 & $52.51-59.77$ & 40.83 & $37.29-44.47$ & 3.00 & $2.01-4.45$ & \multirow[t]{3}{*}{0.061} \\
\hline Divorced or Widow $(n=125)$ & 47.94 & $33.13-63.12$ & 48.40 & $33.59-63.49$ & 3.66 & $1.27-10.11$ & \\
\hline Never married $(n=622)$ & 48.09 & $42.16-54.07$ & 46.27 & $40.41-52.24$ & 5.64 & $3.90-8.10$ & \\
\hline \multicolumn{8}{|l|}{ Income } \\
\hline Low $(n=497)$ & 49.44 & $42.76-56.15$ & 47.41 & $40.77-54.14$ & 3.15 & $1.73-5.65$ & \multirow[t]{3}{*}{0.397} \\
\hline Moderate $(n=1063)$ & 56.92 & $52.23-61.49$ & 39.52 & $35.06-44.16$ & 3.56 & $2.19-5.74$ & \\
\hline High $(\mathrm{n}=803)$ & 53.35 & $47.96-58.67$ & 43.15 & $37.90-48.56$ & 3.49 & $2.24-5.41$ & \\
\hline \multicolumn{8}{|l|}{ Age } \\
\hline less than $25(n=284)$ & 43.88 & $34.50-53.73$ & 49.74 & 40.17-59.32 & 6.38 & $4.17-9.63$ & \multirow[t]{5}{*}{$<0.001$} \\
\hline $25-34(n=845)$ & 47.95 & $42.74-53.21$ & 47.11 & $41.91-52.37$ & 4.94 & $3.13-7.72$ & \\
\hline $35-44(n=667)$ & 61.31 & $55.44-66.87$ & 37.36 & $31.85-43.22$ & 1.33 & $0.67-2.64$ & \\
\hline $45-54(n=377)$ & 59.72 & $51.71-67.25$ & 39.80 & $32.29-47.82$ & 0.48 & $0.15-1.47$ & \\
\hline $55+(\mathrm{n}=201)$ & 60.00 & $48.86-70.20$ & 36.07 & $26.32-47.12$ & 3.93 & $1.28-11.42$ & \\
\hline \multicolumn{8}{|l|}{ Education level } \\
\hline Less than High school $(n=580)$ & 61.77 & $56.12-67.13$ & 35.32 & $30.08-40.94$ & 2.91 & $1.59-5.26$ & \multirow[t]{3}{*}{$0.003^{*}$} \\
\hline High school $(\mathrm{n}=688)$ & 49.90 & $43.91-55.89$ & 45.66 & $39.76-51.69$ & 4.44 & $2.78-7.01$ & \\
\hline Post-Secondary $(\mathrm{n}=1225)$ & 49.46 & $45.26-53.67$ & 47.08 & $42.91-51.29$ & 3.46 & $2.29-5.20$ & \\
\hline \multicolumn{8}{|l|}{ Current Smoker } \\
\hline Yes $(n=624)$ & 55.79 & $49.58-61.81$ & 41.03 & $35.10-47.22$ & 3.19 & $1.80-5.59$ & \multirow[t]{2}{*}{0.814} \\
\hline No $(n=1874)$ & 53.81 & $50.23-57.36$ & 42.55 & $39.07-46.12$ & 3.63 & $2.60-5.04$ & \\
\hline \multicolumn{8}{|l|}{ Physically Active } \\
\hline Yes $(\mathrm{n}=1073)$ & 51.39 & $46.60-56.15$ & 45.06 & $40.37-49.85$ & 3.55 & $2.24-5.57$ & 0.266 \\
\hline No $(n=1426)$ & 56.23 & $52.17-60.21$ & 40.27 & $36.36-44.30$ & 3.50 & $2.42-5.04$ & \\
\hline Number of chronic illness & & & & & & & \\
\hline $0(\mathrm{n}=1173)$ & 49.33 & $44.86-53.80$ & 47.33 & $42.91-51.80$ & 3.34 & $2.28-4.87$ & $0.001^{*}$ \\
\hline $1(\mathrm{n}=725)$ & 54.20 & $48.40-59.89$ & 40.93 & $35.42-46.68$ & 4.87 & $2.89-8.09$ & \\
\hline 2 or more $(n=602)$ & 64.62 & $58.25-70.52$ & 33.00 & $27.22-39.35$ & 2.37 & $1.18-4.70$ & \\
\hline Body Mass Index & & & & & & & \\
\hline Underweight $(\mathrm{n}=69)$ & 45.91 & $29.80-62.92$ & 52.79 & $35.91-69.04$ & 1.31 & $0.46-3.64$ & $0.050^{*}$ \\
\hline Normal Weight $(\mathrm{n}=815)$ & 50.20 & $44.97-55.44$ & 45.37 & $40.23-50.62$ & 4.42 & $2.83-6.85$ & \\
\hline Overweight $(\mathrm{n}=890)$ & 54.41 & $49.20-59.53$ & 42.17 & $37.14-47.37$ & 3.42 & $2.07-5.60$ & \\
\hline Obese $(n=542)$ & 62.42 & $55.52-68.85$ & 35.65 & $29.31-42.54$ & 1.93 & $1.05-3.51$ & \\
\hline Depression (PHQ2) & & & & & & & \\
\hline Yes $(\mathrm{n}=325)$ & 54.05 & $50.67-57.39$ & 42.37 & $39.08-45.72$ & 3.58 & $2.65-4.83$ & 0.911 \\
\hline No $(n=2127)$ & 55.58 & $47.27-63.60$ & 41.41 & $33.52-49.76$ & 3.01 & $1.12-7.86$ & \\
\hline Perceived Health & & & & & & & \\
\hline Poor $(n=878)$ & 59.42 & $54.30-64.34$ & 37.04 & $32.25-42.10$ & 3.54 & $2.10-5.92$ & $0.038^{*}$ \\
\hline Good $(\mathrm{n}=982)$ & 52.55 & $47.50-57.55$ & 44.67 & $39.72-49.71$ & 2.78 & $1.86-4.16$ & \\
\hline Very Good $(n=585)$ & 48.36 & $42.10-54.68$ & 47.79 & $41.54-54.11$ & 3.85 & $2.25-6.50$ & \\
\hline
\end{tabular}

NA: Not Applicable

had lower odds of sleeping $<7$ hrs (OR 0.62, $\mathrm{P}=0.001$ ); Compared to Qataris, lower odds of sleeping $>8 \mathrm{hrs}$ was found in WCEs (OR $0.45, \mathrm{P}=$ 0.009) and BCEs (OR 0.25, P $<0.001$ ). Participants younger than 25 years of age had lower odds of sleeping $<7$ hrs (OR $0.47, \mathrm{P}=0.01$ ) compared to 35-44 year olds. Participants between 25 and 34 years of age had lower odds of sleeping $<7$ hrs (OR 0.59, $\mathrm{P}=0.003$ ) and increased odds of sleeping $>8 \mathrm{hrs}$ (OR 3.23, $\mathrm{P}=0.01$ ) compared to 35-44 year olds. Participants between the ages of 45-55 years had lower odds of sleeping $>8$ hrs compared to 35-44 year olds (OR 0.09, $\mathrm{P}=0.003$ ).

As for other associations shown in Table 2, participants who reported the poorest health status had increased odds of sleeping $<$ 7hrs (OR 1.38, $\mathrm{P}=0.04$ ) compared with those who reported good health. Additionally, participants with two or more diagnosed illnesses had higher odds of sleeping $<7$ hrs (OR 1.58, $\mathrm{P}=0.02$ ) compared to healthy participants. An increase in odds of sleeping $<7 \mathrm{hrs}$ was also observed in participants with obesity (OR 1.58, P0.02). Those who were underweight had lower odds of sleeping $>8 \mathrm{hrs}(\mathrm{OR}=0.24, \mathrm{p}=0.02)$ as compared to normal weight.

No significant associations were found between current smoking status, physical inactivity, and depression status and either short or long sleep durations relative to normal sleep durations (Table 2).

\section{Discussion}

Our findings supported high prevalence of short sleepers (54\%) compared to low prevalence of long sleepers (4\%) in the general population of Qatar. On average, only $42 \%$ of the population reported sleeping between 7 and $8 \mathrm{~h}$ per night. Therefore, Qatar's population exhibited one of the lowest prevalence of normal sleep duration and the highest prevalence of short sleep duration compared to other countries $[14,15,27$, 28]. Qatar continues to witness unprecedented growth in its economy and urban infrastructure, which may contribute to the fast-pace of its society, today.

Our study also showed increased odds of short sleep in those reporting at least two diseases, but no statistically significant increase in the odds of chronic illness among long sleepers. Therefore, our findings did not support a U-shaped association between sleep duration and 
Table 2

Multinomial logistic regression models.

\begin{tabular}{|c|c|c|c|c|c|c|}
\hline \multirow[t]{2}{*}{ Sleep duration } & \multicolumn{3}{|c|}{$\begin{array}{l}\text { Short }(<7 \text { hrs }) \text { Vs Normal } \\
\text { (7-8 hrs) }\end{array}$} & \multicolumn{3}{|c|}{$\begin{array}{l}\text { Long ( > 8hrs) Vs Normal (7-8 } \\
\text { hrs) }\end{array}$} \\
\hline & OR & CI & $\begin{array}{l}\mathrm{P} \text { - } \\
\text { value }\end{array}$ & OR & CI & P-value \\
\hline \multicolumn{7}{|c|}{ Model 1: Socio-economic factors } \\
\hline \multicolumn{3}{|c|}{ Respondent } & & & & \\
\hline Qataris & Ref & & & & & \\
\hline $\begin{array}{l}\text { White collar } \\
\text { Expats }\end{array}$ & 0.62 & $0.47-0.82$ & $0.001^{\mathrm{a}}$ & 0.45 & $0.25-0.81$ & $0.008^{\mathrm{a}}$ \\
\hline $\begin{array}{l}\text { Blue collar } \\
\text { Expats }\end{array}$ & 0.92 & $0.67-1.28$ & 0.63 & 0.25 & $0.12-0.54$ & $<0.001^{\mathrm{a}}$ \\
\hline \multicolumn{7}{|l|}{ Gender } \\
\hline Male & Ref & & & & & \\
\hline Female & 0.86 & $0.63-1.16$ & 0.32 & 1.31 & $0.68-2.50$ & 0.42 \\
\hline \multicolumn{7}{|l|}{ Marital status } \\
\hline Married & Ref & & & & & \\
\hline $\begin{array}{l}\text { Divorced or } \\
\text { Widow }\end{array}$ & 0.92 & $0.44-1.92$ & 0.82 & 0.24 & $0.07-0.81$ & $0.02^{*}$ \\
\hline $\begin{array}{l}\text { Never married } \\
\text { Income }\end{array}$ & 1.05 & $0.73-1.50$ & 0.79 & 0.81 & $0.41-1.57$ & 0.53 \\
\hline Low & 0.77 & $0.53-1.13$ & 0.18 & 0.59 & $0.27-1.31$ & 0.20 \\
\hline Moderate & Ref & & & & & \\
\hline High & 0.80 & $0.58-1.10$ & 0.17 & 1.01 & $0.47-2.15$ & 0.98 \\
\hline \multicolumn{7}{|l|}{ Age } \\
\hline less than 25 & 0.47 & $0.27-0.83$ & $0.01^{\mathrm{a}}$ & 2.83 & $0.92-8.67$ & $0.07^{\mathrm{a}}$ \\
\hline $25-34$ & 0.59 & $0.42-0.84$ & $0.003^{\mathrm{a}}$ & 3.23 & $1.30-8.03$ & $0.01^{\mathrm{a}}$ \\
\hline $35-44$ & Ref & & & & & \\
\hline $45-54$ & 0.94 & $0.62-1.42$ & 0.76 & 0.09 & $0.02-0.43$ & $0.003^{\mathrm{a}}$ \\
\hline \multicolumn{7}{|l|}{ Education } \\
\hline $\begin{array}{l}\text { Less than High } \\
\text { school }\end{array}$ & 1.37 & $0.92-2.04$ & 0.18 & 1.45 & $0.44-4.80$ & 0.55 \\
\hline High school & 0.84 & 0.59-1.19 & 0.32 & 1.78 & $0.76-4.15$ & 0.18 \\
\hline Post-Secondary & Ref & & & & & \\
\hline \multicolumn{7}{|l|}{ Model } \\
\hline \multicolumn{6}{|l|}{ Current } & Smoker \\
\hline Yes & 1.02 & $0.73-1.40$ & 0.93 & 1.17 & $0.51-2.73$ & 0.71 \\
\hline No & Ref & & & & & \\
\hline \multicolumn{7}{|l|}{ Physically } \\
\hline Yes & Ref & & & & & \\
\hline No & 1.08 & $0.83-1.42$ & 0.56 & 1.23 & $0.64-2.36$ & 0.54 \\
\hline \multicolumn{7}{|l|}{$\begin{array}{l}\text { Perceived } \\
\text { wellbeing }\end{array}$} \\
\hline Poor & 1.38 & $1.02-1.88$ & $0.04^{\mathrm{a}}$ & 1.37 & $0.64-2.93$ & 0.41 \\
\hline Good & Ref & & & & & \\
\hline Very Good & 0.74 & $0.52-1.07$ & 0.11 & 1.40 & $0.65-3.01$ & 0.39 \\
\hline \multicolumn{7}{|c|}{$\begin{array}{l}\text { Model 3: } \\
\text { Health }\end{array}$} \\
\hline \multicolumn{7}{|c|}{ Number of chronic illness } \\
\hline None & Ref & & & & & \\
\hline 1 & 1.15 & $0.83-1.60$ & 0.41 & 1.40 & $0.62-3.16$ & 0.42 \\
\hline 2 or more & 1.58 & $1.09-2.31$ & $0.02^{\mathrm{a}}$ & 1.17 & $0.45-3.04$ & 0.74 \\
\hline \multicolumn{7}{|l|}{ Body Mass } \\
\hline Underweight & 0.64 & $0.30-1.36$ & 0.25 & 0.24 & $0.07-0.76$ & $0.02^{\mathrm{a}}$ \\
\hline Normal Weight & Ref & & & & & \\
\hline Overweight & 1.18 & $0.85-1.64$ & 0.33 & 0.96 & $0.47-1.94$ & 0.90 \\
\hline Obese & 1.58 & $1.06-2.35$ & $0.02^{*}$ & 0.55 & $0.24-1.25$ & 0.15 \\
\hline Depression & & & & & & \\
\hline Yes & 0.99 & $0.66-1.49$ & 0.96 & 1.10 & $0.36-3.35$ & 0.87 \\
\hline No & Ref & & & & & \\
\hline
\end{tabular}

a Adjusted for Gender, Age, and respondent group.

chronic disease status. Similar pattern of associations were also observed for obesity status in relation to short and long sleep durations. Participant's social group, age, perceived health, and BMI were found to be strongly associated with sleep duration. However, no association was observed between sleep duration and each of gender, marital status, income, smoking status, physical activity, or depression.

The associations between short sleep duration, chronic illness, and obesity have been consistently documented by previous epidemiological
[5,30,31] and experimental studies [32]. Short sleep has been shown to have an increased inflammatory effect [35], which is also consistent with the role of sleep as a reparative process with anti-oxidative and reparative effects on DNA [33].

A previous study reported positive associations between long sleep duration, chronic illness, and obesity [34]. Additionally, prolonged sleep was associated with a greater risk for these conditions compared to short sleep [37]. However, these findings werexdiu8 not replicated in the current study. Previous studies reported that alcohol consumption could be an important confounding factor especially for the positive association between long sleep and chronic disease [12,15]. This is because alcohol consumption as well as certain medications increase duration of light sleep at the expense of deep reparative sleep [38]. Qatar is a conservative Muslim country, where alcohol consumption is socially unacceptable practice. Although the prevalence of alcohol consumption in Qatar is unknown, it is expected to be lower than that of non-Muslim country, which could explain the weak (positive) and statistically non-significant association between long sleep and chronic disease status observed in this study. Inadequate power is also an equally plausible explanation for the lack of statistical significance in the association between long sleep and chronic disease, which could be due to small number of observations with long sleep duration in our sample.

Similar to other studies, socioeconomic factors play important role [11] with BCEs showing the highest prevalence of short sleep whereas WCEs had the lowest. Surprisingly, there were no statistically significantly differences between BCEs when compared to Qataris for short sleep, which presents a puzzling social phenomenon in Qatar's general population in which the lowest and highest income groups were comparably short sleepers. Several studies showed Asian countries report some of the shortest sleep durations [39-41]. The majority of BCEs in Qatar are from South Asia and South East Asia. The lack of difference in prevalence of short sleep between BCEs and QNs could be due to shared cultural attitudes towards sleep. QNs in our sample had higher prevalence of long sleep duration compared to BCEs, which could be due to employment status as the majority of BCEs were employed, but this was not the case for QNs. Equally, sleep patterns could be driven by differences in working hours and BCEs are more likely to work nightshifts than QNs. In our sample, the highest prevalence of short sleep was found among older participants, while highest prevalence of long sleep was found among participants in the youngest age group. These findings are consistent with previously reported decline in sleep duration with age in the general population [42]. Urbanization, economic growth, and higher working demands have been attributed to shorter duration of sleep in Asian countries [43]. Similarly, Qatar's rapid modernization and economic growth could be contributing to reduced sleep duration in its general population. However, even when compared to similar modernized western countries, Asian countries still have shorter sleep duration that maybe driven to social and cultural differences [44].

Although previous studies report an association between sleep duration and depression [45], this was not the case in the current study. This could be due to the lack of assessment of sleep quality in our study, the self-reported nature of the study, or the lack of awareness of the effect of sleep on mental health.

\subsection{Strengths and limitations}

The strength of the study lies in its nationally representative sample of the adult population in Qatar. Although we observed high prevalence of short sleepers in our sample, the analysis may have lacked power to detect statistically significant effects between long sleep duration and poor health. The cross-sectional nature of the study is a major limitation and causation cannot be inferred. The study adjusted for a number of confounders, however, other important covariates were not measured such as sleep quality and caffeine consumption. Additionally, all variables were based on self-report, which may be subject to social desirability bias. 


\subsection{Implications}

Qatar is a highly diverse country with a multicultural population similar to that of other Gulf countries. There has been little focus on the impact of sleep on health in this part of the world, which is surprising given that sleep habits are largely driven by the social environment. The current study is the first of its kind in such population. Better understanding of socioeconomic differences and sociocultural drivers of sleep behavior can improve public health and aid in design of effective awareness campaigns that target public health in relation to sleep. International guidelines for sleep disorder management recommend educational provision of healthy sleep habits [46]. The results of this study highlight the need for public awareness campaigns focused on importance of sleep for overall health, and optimal lifestyle habits that would help improve sleep quantity and reduce impact of short sleep on health in this population.

\section{Conclusion}

The present study is the first to examine sleep duration in a nationally represented sample of Qatar's adult population and in the EMR region. The results demonstrate high prevalence of short sleep duration, which was associated with poor rated health, obesity, and chronic illness.

\section{Authors' contributions}

All authors jointly contributed to the design of the study. Maryam A. Al-Thani \& Salma M. Khaled contributed to the analysis of data. All authors contributed to the writing of the manuscript. All authors have read and approved the final manuscript.

\section{Declaration of competin interests}

The authors declare that they have no competing interests.

\section{Acknowledgment}

Qatar Diabetes Association sponsored the study.

\section{References}

[1] M.A. Grandner, L. Hale, M. Moore, N.P. Patel, Mortality associated with short sleep duration: the evidence, the possible mechanisms, and the future, Sleep Med. Rev. 14 (3) (2010) 191-203, https://doi.org/10.1016/j.smrv.2009.07.006.

[2] E.C. Hammond, Some preliminary findings ON physical complaints from a prospective study OF 1,064,004 men and women, Am. J. Public Health Nation's Health 54 (1964) 11-23.

[3] L.M. Kurina, M.K. McClintock, J.H. Chen, L.J. Waite, R.A. Thisted, D.S. Lauderdale, Sleep duration and all-cause mortality: a critical review of measurement and associations, Ann. Epidemiol. 23 (6) (2013) 361-370, https://doi.org/10.1016/ j.annepidem.2013.03.015.

[4] Y.S. Bin, N.S. Marshall, N. Glozier, Secular trends in adult sleep duration: a systematic review, Sleep Med. Rev. 16 (3) (2012) 223-230, https://doi.org/ 10.1016/j.smrv.2011.07.003

[5] G.M. Anic, L. Titus-Ernstoff, P.A. Newcomb, A. Trentham-Dietz, K.M. Egan, Sleep duration and obesity in a population-based study, Sleep Med. 11 (5) (2010) 447-451, https://doi.org/10.1016/j.sleep.2009.11.013.

[6] N.S. Marshall, Y.S. Bin, N. Glozier, Sleeping at the limits: the changing prevalence of short and long sleep durations in 10 countries, Am. J. Epidemiol. 177 (8) (2013) 826-833, https://doi.org/10.1093/aje/kws308.

[7] L. Matricciani, Y.S. Bin, T. Lallukka, E. Kronholm, D. Dumuid, C. Paquet, T. Olds, Past, present, and future: trends in sleep duration and implications for public health, Sleep Health 3 (5) (2017) 317-323, https://doi.org/10.1016/j sleh.2017.07.006.

[8] F.S. Luyster, P.J. Strollo Jr., P.C. Zee, J.K. Walsh, Boards of directors of the American academy of sleep, M., \& the sleep research, S, Sleep: a health imperative. Sleep 35 (6) (2012) 727-734, https://doi.org/10.5665/sleep.1846.

[9] A.M. Chang, D. Aeschbach, J.F. Duffy, C.A. Czeisler, Evening use of light-emitting eReaders negatively affects sleep, circadian timing, and next-morning alertness, Proc. Natl. Acad. Sci. U. S. A. 112 (4) (2015) 1232-1237, https://doi.org/10.1073/ pnas.1418490112.

[10] F.P. Cappuccio, M.A. Miller, Sleep and cardio-metabolic disease, Curr. Cardiol. Rep. 19 (11) (2017) 110, https://doi.org/10.1007/s11886-017-0916-0.
[11] M.A. Grandner, Sleep, health, and society, Sleep Med Clin 12 (1) (2017) 1-22, https://doi.org/10.1016/j.jsmc.2016.10.012.

[12] S.R. Patel, A. Malhotra, D.J. Gottlieb, D.P. White, F.B. Hu, Correlates of long sleep duration, Sleep 29 (7) (2006) 881-889.

[14] T. Lallukka, L. Sares-Jäske, E. Kronholm, K. Sääksjärvi, A. Lundqvist, T. Partonen, P. Knekt, Sociodemographic and socioeconomic differences in sleep duration and insomnia-related symptoms in Finnish adults, BMC Publ. Health 12 (2012), 565565, https://doi.org/10.1186/1471-2458-12-565.

[15] M.-S. Lee, J.-S. Shin, J. Lee, Y.J. Lee, M.-r. Kim, K.B. Park, I.-H. Ha, The association between mental health, chronic disease and sleep duration in Koreans: a crosssectional study, BMC Publ. Health 15 (2015), 1200-1200, https://doi.org/10.1186/ s12889-015-2542-3.

[16] A.J. Ferrari, F.J. Charlson, R.E. Norman, S.B. Patten, G. Freedman, C.J.L. Murray, H.A. Whiteford, Burden of depressive disorders by country, sex, age, and year: findings from the global burden of disease study 2010, PLoS Med. 10 (11) (2013), e1001547, https://doi.org/10.1371/journal.pmed.1001547.

[17] S. Al-Kandari, A. Alsalem, S. Al-Mutairi, D. Al-Lumai, A. Dawoud, M. Moussa, Association between sleep hygiene awareness and practice with sleep quality among Kuwait University students, Sleep Health 3 (5) (2017) 342-347, https:// doi.org/10.1016/j.sleh.2017.06.004.

[18] A.I. Almojali, S.A. Almalki, A.S. Alothman, E.M. Masuadi, M.K. Alaqeel, The prevalence and association of stress with sleep quality among medical students, J Epidemiol Glob Health 7 (3) (2017) 169-174, https://doi.org/10.1016/ j.jegh.2017.04.005

[19] J.A. Mindell, C. Lee, A. Sadeh, Young child and maternal sleep in the Middle East, Sleep Med. 32 (2017) 75-82, https://doi.org/10.1016/j.sleep.2016.11.011.

[20] A.E. Ahmed, F. Al-Jahdali, A. AlAlwan, F. Abuabat, S.A. Bin Salih, A. Al-Harbi, H. Al-Jahdali, Prevalence of sleep duration among Saudi adults, Saudi Med. J. 38 (3) (2017) 276-283, https://doi.org/10.15537/smj.2017.3.17101.

[21] R.J. Casady, J.M. Lepkowski, Stratified telephone survey designs, Surv. Methodol 19 (1) (1993) 103-113.

[22] Qatar statistics Authority. (2018). Retrieved from Error! Hyperlink reference not valid.

[23] P. Heslop, G.D. Smith, C. Metcalfe, J. Macleod, C. Hart, Sleep duration and mortality: the effect of short or long sleep duration on cardiovascular and all-cause mortality in working men and women, Sleep Med. 3 (4) (2002) 305-314.

[24] T. Lallukka, R. Kaikkonen, T. Harkanen, E. Kronholm, T. Partonen, O. Rahkonen, S. Koskinen, Sleep and sickness absence: a nationally representative register-based follow-up study, Sleep 37 (9) (2014) 1413-1425, https://doi.org/10.5665/ sleep.3986.

[25] B. Lowe, K. Kroenke, K. Grafe, Detecting and monitoring depression with a two-item questionnaire (PHQ-2), J. Psychosom. Res. 58 (2) (2005) 163-171, https://doi.org/ 10.1016/j.jpsychores.2004.09.006.

[26] K. Kroenke, R.L. Spitzer, J.B.W. Williams, B. Löwe, The patient health questionnaire somatic, anxiety, and depressive symptom scales: a systematic review, Gen. Hosp. Psychiatr. 32 (4) (2010) 345-359, https://doi.org/10.1016/ j.genhosppsych.2010.03.006.

[27] C.A. Magee, D.C. Iverson, P. Caputi, Factors associated with short and long sleep, Prev. Med. 49 (6) (2009) 461-467, https://doi.org/10.1016/j.ypmed.2009.10.006.

[28] A. Steptoe, V. Peacey, J. Wardle, Sleep duration and health in young adults, Arch. Intern. Med. 166 (16) (2006) 1689-1692, https://doi.org/10.1001/ archinte.166.16.1689.

[30] Y. Liu, J.B. Croft, A.G. Wheaton, G.S. Perry, D.P. Chapman, T.W. Strine, L. PresleyCantrell, Association between perceived insufficient sleep, frequent mental distress, obesity and chronic diseases among US adults, 2009 behavioral risk factor surveillance system, BMC Publ. Health 13 (2013) 84, https://doi.org/10.1186/ 1471-2458-13-84.

[31] S.R. Patel, D. Sotres-Alvarez, S.F. Castaneda, K.A. Dudley, L.C. Gallo, R. Hernandez, P.C. Zee, Social and health correlates of sleep duration in a US hispanic population: results from the hispanic community health study/study of latinos, Sleep 38 (10) (2015) 1515-1522, https://doi.org/10.5665/sleep.5036.

[32] M.R. Irwin, R. Olmstead, J.E. Carroll, Sleep disturbance, sleep duration, and inflammation: a systematic review and meta-analysis of cohort studies and experimental sleep deprivation, Biol. Psychiatr. 80 (1) (2016) 40-52, https:// doi.org/10.1016/j.biopsych.2015.05.014.

[33] A. Galano, D.X. Tan, R.J. Reiter, Melatonin: a versatile protector against oxidative DNA damage, Molecules 23 (3) (2018), https://doi.org/10.3390/ molecules23030530.

[34] M. Jike, O. Itani, N. Watanabe, D.J. Buysse, Y. Kaneita, Long sleep duration and health outcomes: a systematic review, meta-analysis and meta-regression, Sleep Med. Rev. 39 (2018) 25-36, https://doi.org/10.1016/j.smrv.2017.06.011.

[35] J.M. Mullington, N.S. Simpson, H.K. Meier-Ewert, M. Haack, Sleep loss and inflammation, Best Pract. Res. Clin. Endocrinol. Metabol. 24 (5) (2010) 775-784, https://doi.org/10.1016/j.beem.2010.08.014.

[37] T.Z. Liu, C. Xu, M. Rota, H. Cai, C. Zhang, M.J. Shi, X. Sun, Sleep duration and risk of all-cause mortality: a flexible, non-linear, meta-regression of 40 prospective cohort studies, Sleep Med. Rev. 32 (2017) 28-36, https://doi.org/10.1016/ j.smrv.2016.02.005.

[38] R. Naiman, Dreamless: the silent epidemic of REM sleep loss, Ann. N. Y. Acad. Sci. 1406 (1) (2017) 77-85, https://doi.org/10.1111/nyas.13447.

[39] K. Peltzer, S. Pengpid, Sleep duration and health correlates among university students in 26 countries, Psychol. Health Med. 21 (2) (2016) 208-220, https:// doi.org/10.1080/13548506.2014.998687.

[40] S. Stranges, W. Tigbe, F.X. Gómez-Olivé, M. Thorogood, N.-B. Kandala, Sleep problems: an emerging global epidemic? Findings from the INDEPTH WHO-sage 
study among more than 40,000 older adults from 8 countries across africa and Asia, Sleep 35 (8) (2012) 1173-1181, https://doi.org/10.5665/sleep.2012.

[41] J. Whinnery, N. Jackson, P. Rattanaumpawan, M.A. Grandner, Short and long sleep duration associated with race/ethnicity, sociodemographics, and socioeconomic position, Sleep 37 (3) (2014) 601-611, https://doi.org/10.5665/sleep.3508.

[42] G.D.M. Potter, D.J. Skene, J. Arendt, J.E. Cade, P.J. Grant, L.J. Hardie, Circadian rhythm and sleep disruption: causes, metabolic consequences, and countermeasures, Endocr. Rev. 37 (6) (2016) 584-608, https://doi.org/10.1210/ er.2016-1083.

[43] X.L. Cao, S.B. Wang, B.L. Zhong, L. Zhang, G.S. Ungvari, et al., The prevalence of insomnia in the general population in China: a meta-analysis, PloS One 12 (2) (2017), e0170772, https://doi.org/10.1371/journal.pone.0170772.
[44] J.C. Lo, R.L. Leong, K.K. Loh, D.J. Dijk, M.W. Chee, Young adults' sleep duration on work days: differences between East and west, Front. Neurol. 5 (2014) 81, https:// doi.org/10.3389/fneur.2014.00081. (Accessed 28 May 2014).

[45] L. Zhai, H. Zhang, D. Zhang, Sleep duration and depression among adults: a metaanalysis of prospective studies, Depress. Anxiety 32 (9) (2015) 664-670, https:// doi.org/10.1002/da.22386.

[46] American Academy of Sleep Medicine, The International Classification of Sleep Disorders (ICSD), Revised. Diagnostic and Coding Manual, Second, 2001, pp. 1-378. Chicago. 